\title{
Production of Glucosamine Hydrochloride from
}

\section{Crustacean Shell}

\author{
Martha Benavente ${ }^{1,2}$, Selene Arias $^{1}$, Luis Moreno ${ }^{2}$ and Joaquín Martínez ${ }^{2}$ \\ 1 Department of Chemical Engineering, National University of Engineering, Managua 5595, Managua, Nicaragua \\ 2 School of Chemical Science and Engineering, KTH Royal Institute of Technology, SE-100 44, Stockholm, Sweden
}

\begin{abstract}
The use of chitin as raw material to obtain glucosamine hydrochloride at laboratory level was investigated. Chitin was extracted from shrimp shells by deproteinization, demineralization and depigmentation. Afterwards, glucosamine hydrochloride was produced in four main stages: (1) acid hydrolysis of chitin with $12 \mathrm{M}$ hydrochloric acid using the reflux technique; (2) filtration of the solution to discard solid impurities; (3) recrystallization of the product using $95 \%$ ethyl alcohol as solvent, and (4) filtration, washing and drying of final product at $50{ }^{\circ} \mathrm{C}$. The FTIR spectrum of the product was compared to a commercial glucosamine hydrochloride of $99.86 \%$ purity, and a coincidence between $96.90 \%$ and $99.66 \%$ was obtained. The influence of temperature, solid/liquid ratio $(\mathrm{g} / \mathrm{mL}$ ), and agitation (with-without) on acid hydrolysis was studied. The best correlation corresponds to the hydrolysis product obtained at solid/liquid ratio of $1: 20$, temperature of $85{ }^{\circ} \mathrm{C}$, and with agitation. The yields of glucosamine hydrochloride with respect to chitin were $42,58,36$ and $48 \%$ for solid/liquid ratios of 1:10, 1:20, 1:30, and 1:40 respectively, at high hydrolysis reaction temperature and with agitation. These results showed that in the range examined, glucosamine hydrochloride with high quality is produced with solid/liquid ratio of 1:20.
\end{abstract}

Key words: Acid hydrolysis, chitin, glucosamine, reflux technique, shrimp shells.

\section{Introduction}

D-glucosamine

$\left(\mathrm{C}_{6} \mathrm{H}_{13} \mathrm{NO}_{5}\right)$

or

2-amino-2-deoxy-D-glucose is an amino sugar (hexosamine) with a molecular weight of 179.17, naturally present in human body and crustacean shells. It is a precursor of biochemical synthesis of the GAGs (glycosaminoglycans) found in cartilage. Premature loss of cartilage is part of the clinical syndrome recognized as OA (osteoarthritis) [1].

Glucosamine in the form of glucosamine sulphate, glucosamine hydrochloride, or $\mathrm{N}$-acetyl-glucosamine is extensively used as a dietary supplement in the treatment for osteoarthritis, knee pain, and back pain $[2,3]$, and a critical evaluation indicated that glucosamine is safe under current conditions of use and does not affect glucose metabolism [4].

Glucosamine can be prepared by acid hydrolysis [5,

Corresponding author: Martha Benavente, LicEng in chemical engineering, research field: process and environmental engineering. E-mail: bena@kth.se.
6] using strong mineral acids or by enzymatic hydrolysis [7] using bacterial chitinase. Different methods for acid hydrolysis of chitin to produced glucosamine hydrochloride (G-HCl) have been studied. Leite et al. [5] used the reflux technique to hydrolyze chitin with 37\% hydrochloric acid (1:5 S/L ratios) at $100{ }^{\circ} \mathrm{C}$ and under different reaction times. Novikov [6] carried out the acid hydrolysis of chitin and chitosan with $36.5 \% \mathrm{HCl}$ at 50 and $70^{\circ} \mathrm{C}$. Li et al. [8] increased the temperature from 60 to $90{ }^{\circ} \mathrm{C}$ to optimize the preparation process of $\mathrm{G}-\mathrm{HCl}$.

Although glucosamine can be produced from different natural sources, e.g., chitin and fermentation of corn and wheat, the most effective one is derived from chitin of shellfish [9]. Chitin is a natural polysaccharide, no toxic, biodegradable and is part of the structural material of the fungal cell walls, insect exoskeletons and crustacean shells. Chitin and its derivative chitosan have a wide range of applications in different areas such as agriculture, drinking water 
and wastewater treatment, food and beverages, cosmetics and toiletries, biomedics and pharmaceutics, fibres and textiles, and paper technology [10].

Nicaragua produces thousands of tons of crustaceans such as shrimps and prawns annually [11] and the waste shells, the raw material to produce chitin constitute approximately $40 \%-50 \%$ of the total weight [12]. Currently, the wastes from seafood factory operations are available in large quantities. The use of these waste shells can be a low cost alternative to obtain valuable products such as chitin, chitosan and G-HCl.

The aim of this work is the use of crustacean shell as raw material to obtain glucosamine hydrochloride at laboratory level. For this purpose, chitin was extracted from shrimp shells using a chemical treatment, and glucosamine hydrochloride was produced by acid hydrolysis of chitin with $12 \mathrm{M}$ hydrochloric acid using the reflux technique.

\section{Materials and Methods}

\subsection{Materials}

Shrimp waste (head, legs, shell, and tail) was provided by Camanica (PESCANOVA Group), a shrimp processing facility located in Chinandega, Nicaragua.

Chitin and D-Glucosamine $\mathrm{HCl}$ was purchased from Jining Green Group Co. Ltd, Shandong, China. D-Glucosamine $\mathrm{HCl}$ is a white crystalline free flowing powder with a $99.86 \%$ purity and -400 mesh particle size.

\subsection{Chitin Extraction}

Chitin was extracted from shrimp waste by desproteinization, demineralization and depigmentation at laboratory level. The Fig. 1 shows a block diagram of the overall process. The raw material was first submerged in $10 \%$ (wt) $\mathrm{NaOH}$ solution for 2 $\mathrm{h}$ with constant agitation to remove proteins. The desproteinized material was then demineralized using $1.8 \mathrm{~mol} / \mathrm{L} \mathrm{HCl}$ solution for $12 \mathrm{~h}$ and subsequently, the product was submerged in 0.38 wt $\%$ NaClO solution for $1 \mathrm{~h}$ with agitation to remove pigments. Chitin was washed several times using distilled water until $\mathrm{pH}$ between 6 and 7 was achieved and dried at $50^{\circ} \mathrm{C}$ during 10 h. Finally, chitin was milled and screened to select the fraction of particles with a size lower than $0.22 \mathrm{~mm}$.

\subsection{Glucosamine Hydrochloride Production}

According to block diagram in Fig. 1, the principal stages for G-HCl production from chitin were: (1) acid hydrolysis of polysaccharide; (2) filtration of the solution, (3) recrystallization of the product, and (4) filtration, washing and drying of final product at $50^{\circ} \mathrm{C}$.

The acid hydrolysis procedure was performed with $12 \mathrm{M}$ hydrochloric acid using the reflux technique according to the procedure in Ref. [4]. However, in preliminary experiments under these conditions (hydrolysis for $1 \mathrm{~h}$ at $100^{\circ} \mathrm{C}$ ) it was observed that the results were not satisfactory because $\mathrm{HCl}$ was consumed very rapidly in the first minutes of the reaction. Based on this experience, the acid hydrolysis was carried out in two experimental sets at different conditions (Table 1): (1) two different solid/liquid ratios, at different temperatures and agitation (with and without) and (2) different solid/liquid ratios, at temperatures range of $68-85{ }^{\circ} \mathrm{C}$ and with agitation. $\mathrm{HCl}$ was previously heated to $60^{\circ} \mathrm{C}$ before the addition of chitin, according to procedure in Ref. [7]. All experiments were carried out in duplicate.

The process for $\mathrm{G}-\mathrm{HCl}$ production was performed as follows: $1 \mathrm{~g}$ of chitin and an amount of $12 \mathrm{M} \mathrm{HCl}$ (depending on solid/liquid ratio) were introduced into a $150 \mathrm{~mL}$ reflux vessel. The mixture was kept at the given temperatures until the solid was completely dissolved. The resulting hydrolyzed was filtered by gravity through a VWR Grade 474 filter paper to remove the solid particles present in solution, and it was left to crystallize at room temperature $\left(25 \pm 2^{\circ} \mathrm{C}\right)$ by 25 days. In order to increase the crystallization rate, ethyl alcohol (15 mL, $w=95 \%)$ was added, and the 


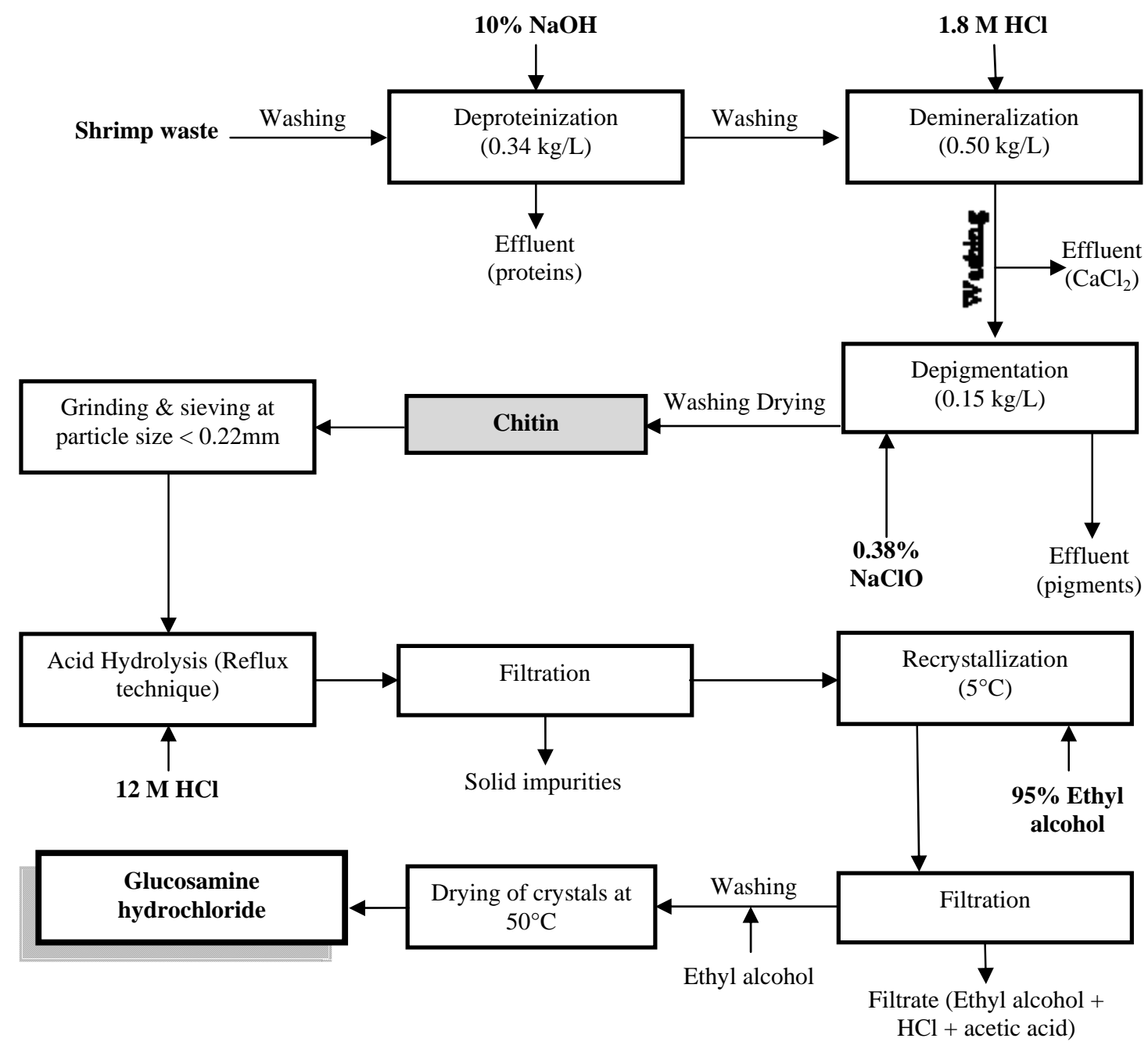

Fig. 1 Block diagram for the extraction of chitin from shrimp shells and production of glucosamine hydrochloride.

Table 1 Work conditions in each experiment set for acid hydrolysis of chitin.

\begin{tabular}{lllllc}
\hline \multicolumn{5}{c}{ Experiment set 1 } & Experiment set 2 \\
\hline Exp No. & Solid/liquid ratio & Temperature $\left({ }^{\circ} \mathbf{C}\right)$ & Agitation & Exp No. & Solid/liquid ratio \\
1.1 & $1: 10$ & 40 & Without & 2.1 & $1: 10$ \\
1.2 & $1: 10$ & 68 & With & 2.2 & $1: 20$ \\
1.3 & $1: 20$ & 58 & Without & 2.3 & $1: 30$ \\
1.4 & $1: 20$ & 85 & With & 2.4 & $1: 40$ \\
\hline
\end{tabular}

resulting mixture was cooled to $5^{\circ} \mathrm{C}$ for 15 days. The mixture was once more filtered, and the solid crystals were washed with ethyl alcohol and dried at $50{ }^{\circ} \mathrm{C}$ in an oven for $12 \mathrm{~h}$.

\subsection{Collection of FTIR Spectra}

The spectra of chitin and G-HCl obtained in these experiments were compared with the commercial references. A Bruker Optics ALPHA FT-IR spectrometer was used to determine their spectra. A spectral range between 400 and $4,000 \mathrm{~cm}^{-1}$ was used.

\section{Results and Discussion}

\subsection{Chitin Characterization}

The principal components of shrimp shells such as proteins, calcium minerals, and pigments were 
removed to get chitin as final product. The average content of chitin in the raw material (dry basis) was $25 \%$. The identification of chitin by comparing its FTIR spectrum with that of a reference sample showed a correlation coefficient of $95 \%$.

Fig. 2 shows FTIR spectrum of product in the 4,000-400 $\mathrm{cm}^{-1}$ region where the different characteristic bands of the molecular structure of $\alpha$-chitin can be identified. The fundamental vibrations are due to $\mathrm{O}-\mathrm{H}$ and $\mathrm{N}-\mathrm{H}$ stretching band (in the range 3,700-3,000 $\mathrm{cm}^{-1}$ ), $\mathrm{C}-\mathrm{H}$ stretching band (in $3,000-2,850 \mathrm{~cm}^{-1}$ ) and carbonyl group (in 1,830-1,650 $\mathrm{cm}^{-1}$ ). In last range, two peaks are displayed: one which is attributed to the occurrence of intermolecular hydrogen bond $\mathrm{CO} \cdots \mathrm{HN}$ at $1,660 \mathrm{~cm}^{-1}$ and another due to the intramolecular hydrogen bond $\mathrm{CO} \cdots \mathrm{HOCH}_{2}$ at $1,625 \mathrm{~cm}^{-1}$. The band split is used to distinguish between $\alpha$-chitin and $\beta$-chitin since a single band is observed in case of the $\beta$-chitin at $1,656 \mathrm{~cm}^{-1}$ [13].

\subsection{Glucosamine Production and Characterization}

The influence of temperature, solid/liquid ratio (g/mL), and agitation (with-without) on acid hydrolysis was studied. During the hydrolysis process, it was observed that chitin was completely dissolved in a period of 3 to $18 \mathrm{~min}$, and immediately after that the solution darkens, becoming a brown colour. The dissolution of chitin was influenced by temperature and agitation. The hydrolysis reaction was faster when the mixture was agitated and temperature was high.
The change to brown colour in solutions can be caused by the Maillard reaction which involves amino groups reacting with an aldehyde and can lead to colour change associated with hydrolysis of chitin [14].

The hydrolysis process involves two acid-catalyzed hydrolysis reactions: the glycosidic linkage (depolymerisation) and the $N$-acetyl linkage (deacetylation). Hackman [15] observed that most of the degradation of the chitin chain occurred during the first few minutes, and that the products formed were oligosaccharides. Fig. 3 illustrates the most accepted reaction mechanism for the acid catalyzed hydrolysis of a glycosidic linkage $\left(\mathrm{S}_{\mathrm{N}} 1\right)$ and the reaction mechanism for the acid-catalyzed hydrolysis of the $N$-acetyl linkage $\left(\mathrm{S}_{\mathrm{N}} 2\right.$ reaction $)[16,17]$.

It was observed that the recrystallization process was slow at room temperature $\left(25 \pm 2{ }^{\circ} \mathrm{C}\right)$. Therefore, in order to increase the crystallization rate and favour the crystal formation, the mixture was cooled to $5^{\circ} \mathrm{C}$ and $95 \%$ ethyl alcohol was added as solvent. The results showed that the crystallization time decreased and the crystals formed were thinner, clearer and brighter in these conditions. According to Myerson [18], the solvent can have a significant effect on the solubility of the solute, the structure and crystal size, as well as morphology and purity of the crystals. Temperature plays an important role in crystallization since it can influence nucleation and crystal growth via its effects on the solubility and supersaturation of the

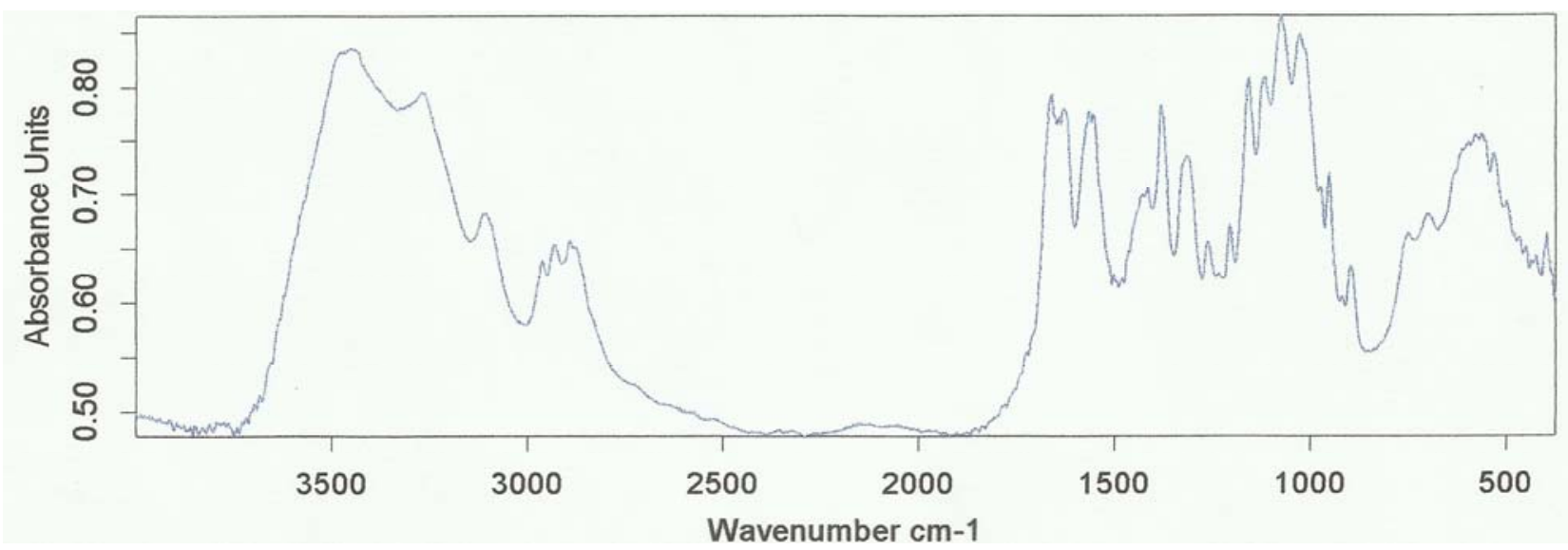

Fig. 2 FTIR spectra of $\alpha$-chitin produced from shrimp waste (head, legs, shell, and tail). 
(a)

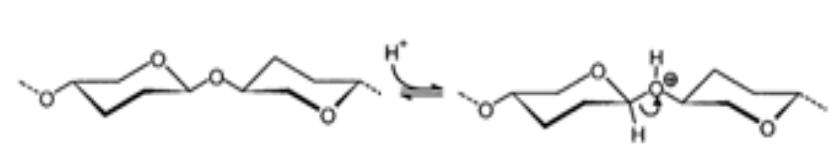

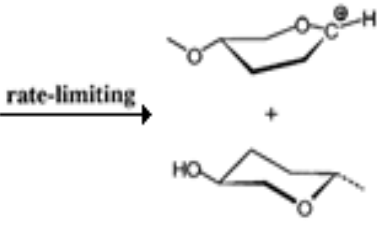<smiles></smiles>

(b)
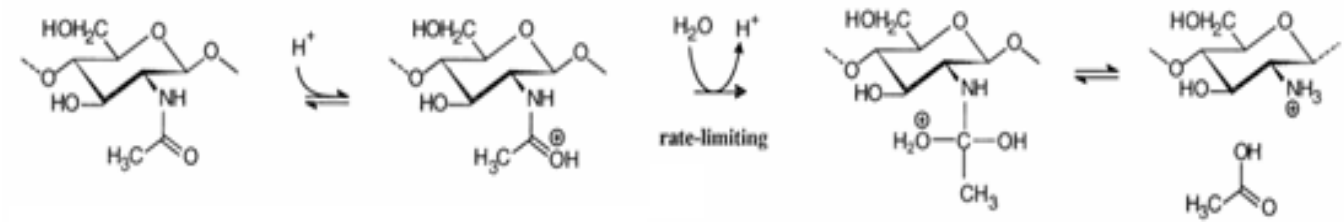

Fig. 3 Schematic illustration of the proposed reaction mechanism for (a) the acid-catalyzed hydrolysis of the glycosidic linkage in chitosan [16] and (b) for the acid-catalyzed hydrolysis of the $\mathrm{N}$-acetyl linkage [17].

Table 2 Results of the glucosamine hydrochloride production according to experimental conditions of set 1.

\begin{tabular}{llll}
\hline Exp No. & Solid/liquid ratio & Yield (\%) & FTIR spectrum correlation* (\%) \\
\hline 1.1 & $1: 10$ & 34.0 & 96.90 \\
1.2 & $1: 10$ & 42.0 & 98.76 \\
1.3 & $1: 20$ & 56.0 & 99.53 \\
1.4 & $1: 20$ & 58.0 & 99.66 \\
\hline
\end{tabular}

*With regard to the commercial reference.

Table 3 Glucosamine hydrochloride production at different solid/liquid ratio at $68-85{ }^{\circ} \mathrm{C}$ and with agitation.

\begin{tabular}{llll}
\hline Exp No. & Solid/liquid ratio & Yield (\%) & FTIR spectrum correlation* (\%) \\
\hline 2.1 & $1: 10$ & 42 & 98.76 \\
2.2 & $1: 20$ & 58 & 99.66 \\
2.3 & $1: 30$ & 36 & 99.36 \\
2.4 & $1: 40$ & 48 & 99.14 \\
\hline
\end{tabular}

*With regard to the commercial reference.

sample.

Table 2 shows the results of the yields of $\mathrm{G}-\mathrm{HCl}$ and the correlation coefficient for the comparison between the product and the reference for the experiments of set 1 . In general, the results showed that the yield of $\mathrm{G}-\mathrm{HCl}$ can increase with temperature and the agitation of the sample. The increase of temperature and the use of agitation lend to the result that chitin dissolves faster and this can contribute to a more effective hydrolysis.

Table 3 shows the results at different solid/liquid ratios, and in a temperatures range of $68-85{ }^{\circ} \mathrm{C}$ and with agitation. We can observe that the yields of G-HCl with respect to chitin were 42, 58, 36 and 48\% for solid/liquid ratios of $1: 10,1: 20,1: 30$, and $1: 40$ respectively. The best yield was obtained at solid/liquid ratio of $1: 20$. The production of $\mathrm{G}-\mathrm{HCl}$ is greatly influenced by the experimental conditions; however, it is not possibly to extract a conclusive tendency from the experiments.

The FTIR spectra were also compared and a coincidence between $98.76 \%$ and $99.66 \%$ was obtained. The highest correlation corresponds to the hydrolysis product obtained at solid/liquid ratio of $1: 20$.

\subsection{FTIR Analysis of Glucosamine Hydrochloride} ( $\mathrm{G}-\mathrm{HCl})$

The FTIR spectra provided by Bruker Optics ALPHA FT-IR spectrometer, were used to identify 

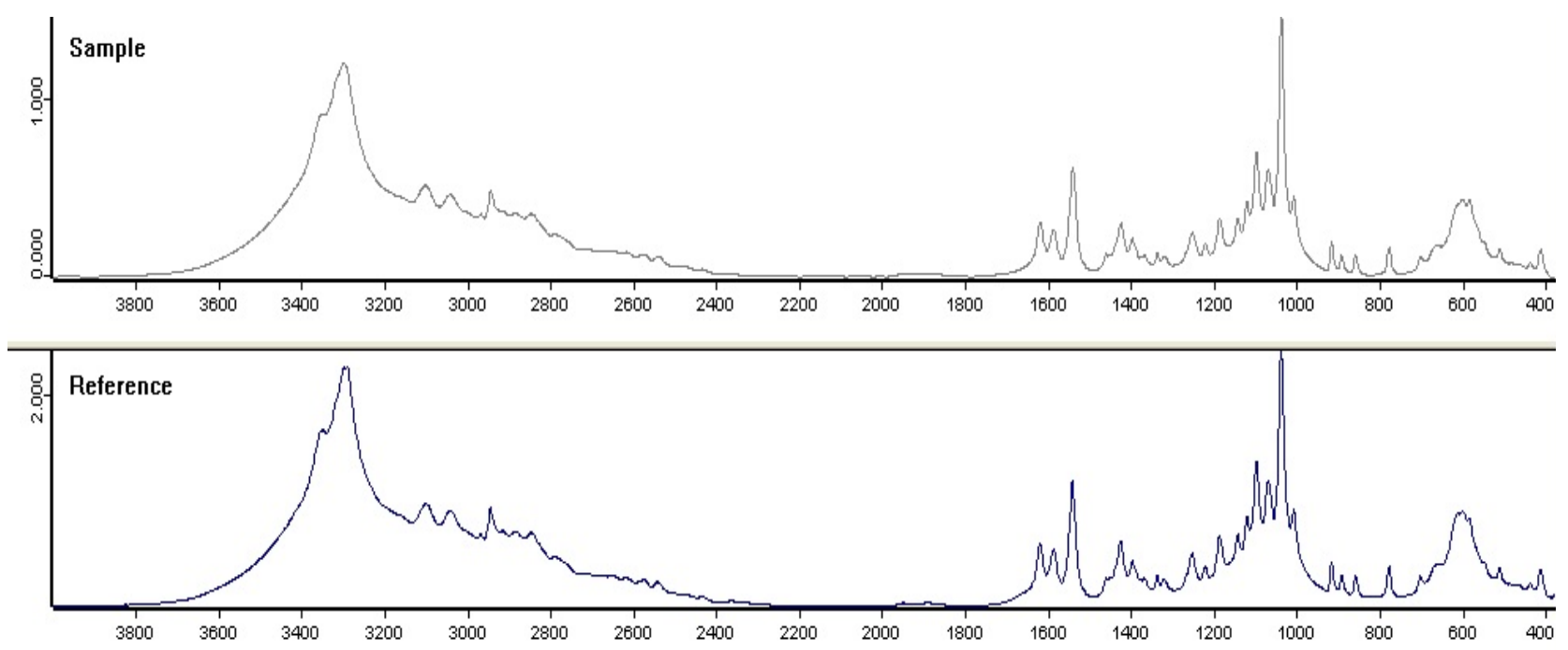

Fig. 4 FTIR spectra of glucosamine hydrochloride produced under Exp 2.2 conditions (Sample) and D-glucosamine HCl from Jining Green Group Co. Ltd (reference).

the product and determine the degree of similarity. The results of the comparison between the spectra of G-HCl products and the commercial reference revealed that a coincidence between 96.90 and 99.66\% was obtained. The highest correlation corresponds to the hydrolysis product obtained at solid/liquid ratio of $1: 20$, temperature of $85{ }^{\circ} \mathrm{C}$, and with agitation (Exp 2.2). Lower values were obtained for lower temperature, larger solid/liquid ratio and without agitation. These results showed that in the range examined, G-HCl with high quality is produced with solid/liquid ratio of 1:20.

The FTIR spectra of G-HCl produced under the work conditions of Exp 2.2 (sample) and G-HCl commercial reference are displayed in Fig. 3. It shows that the FTIR spectra of both materials are essentially identical with regard to the band-positions of G-HCl main groups. This fact is confirmed by the correlation coefficient of $99.66 \%$ which indicates a very high degree of similarity between sample spectrum and the reference spectrum.

The FTIR spectrum of G-HCl produced (sample in Fig. 4) exhibits an intense band at 3,370-3,300 $\mathrm{cm}^{-1}$ associated with the $\mathrm{O}-\mathrm{H}$ and $\mathrm{N}-\mathrm{H}$ stretching, a $\mathrm{NH}_{2}$ scissoring band at $1,615 \mathrm{~cm}^{-1}$ and at $1,094 \mathrm{~cm}^{-1}$ due to secondary alcohol $-\mathrm{OH}$.

\section{Conclusions}

In conclusion, these results showed that in the range examined, G-HCl with good quality is produced with solid/liquid ratio of $1: 20$, at high hydrolysis reaction temperature and with agitation. Additionally, the low temperature $\left(5^{\circ} \mathrm{C}\right)$ and the use of ethyl alcohol support the formation of $\mathrm{G}-\mathrm{HCl}$ crystals. Although, it is possible to convert waste materials into valuable products such as glucosamine, more experimental work should be carried out to optimize the process. As well, additional information about biological and chemical behaviour should be necessary in order to assure if this product is suitable for dietary supplement.

\section{Acknowledgements}

The financial support of the Swedish International Developments Cooperation Agency (Sida) is gratefully acknowledged.

\section{References}

[1] Clegg, D. O., and Jackson, Ch. G. 2005. “Glusosamine.” In Encyclopedia of Dietary Supplements, edited by Coates, P. M., Blackman, M. R., Cragg, G., Levine, M., Moss, J., and White, J. D. New York: Marcel Dekker.

[2] Houpt, J. B., McMillan, R., Wein, C., and Paget-Dellio, S. D. 1999. "Effect of Glucosamine Hydrochloride in the 
Treatment of Pain of Osteoarthritis of the Knee." $J$. Rheumatol. 26: 2423-30.

[3] Luo, J., Hu, Y. S., Wu, Y., and Fan, W. K. 2005. "Effect of Glucosamine Hydrochloride in Ameliorating Knee Osteoarthritis.” Chin. J. Clini. Rehabil. 9: 70-2.

[4] Anderson, J. W., Nicolosi, R. J., and Borzelleca, J. F. 2005. "Glucosamine Effects in Humans: A Review of Effects on Glucose Metabolism, Side Effects, Safety Considerations and Efficacy.” Food Chem. Toxicol. 43: 187-201.

[5] Leite, A., Silveira, I., Matos, V., Matos, J., Monteiro-Moreira, A., and Mafezoli, J. 2002. "Optimization of synthesis, physical and chemical analysis and use in an experimental model of glucosamine hydrochloride and glucosamine.” In: VI Northeast Regional Meeting SBBQ, Fortaleza, Brazil.

[6] Novikov, V. Y. 2004. "Acid Hydrolysis of Chitin and Chitosan.” Russ. J. Appli. Chem. 77: 484-7.

[7] Pichyangkura, R., Kudan, S., Kuttiyawong, K., Sukwattanasinitt, M., and Aiba, S. I. 2002. "Quantitative Production of 2-Acetamido-2-Deoxy-D-Glucose from Crystalline Chitin by Bacterial Chitinase.” Carbohydr. Res. 337: 557-9.

[8] Li, J.-l., Zhou, Y., Zhang, M., and Zhang, H.-b. 2007. "Optimization of Prepartion Process of Glucosamine Hydrochloride.” Anhui Med. Pharm. J. 11 (1) 11-2.

[9] Shahidi, F., Arachchi, J. K. V., and Jeon Y.-J. 1999. "Food Applications of Chitin and Chitosans." Trends in Food Sci. Technol. 10: 37-51.
[10] Ravi Kumar, M. N. V. 2000. "A Review of Chitin and Chitosan Applications.” React. Funct. Polym. 46: 1-27.

[11] CETREX 2010. All Products Export: January-December 2008/2009. Republic of Nicaragua.

[12] Xu, Y., Gallert, C. and Winter, J. 2008. "Chitin Purification from Shrimp Wastes by Microbial Deproteination and Decalcification.” Appl. Microbiol. Biotechnol. 79: 687-97.

[13] Sagheer, F. A. A., Al-Sughayer, M. A., Muslim, S., and Elsabee M. Z. 2009. "Extraction and Characterization of Chitin and Chitosan from Marine Sources in Arabian Gulf.” Carbohydr. Polym. 77: 410-9.

[14] Pettersen H., Sannes A., Holme H. K., Kristensen Å. H., Dornish, M., and Smidsrød, O. 2000. "Thermal Depolymerization of Chitosan Salts." In Advances in Chitin Science, edited by Peter, M. G., Domard, A., and Muzzarelli R. A. A., Vol. 4. Postdam: University of Potsdam, 422-8.

[15] Hackman, R. H. 1962. "Studies on Chitin V: Action of Mineral Acids on Chitin.” Aust. J. Biol. Sci. 15: 526-32.

[16] Edward J. T. 1955. "Stability of Glycosides to Acid Hydrolysis-A Conformational Analysis.” Chem. Ind. 36: 1102-4.

[17] Stryer, L. 1995. Biochemistry, 4th ed., New York: W.H. Freeman and Company.

[18] Myerson, A. S. 2001. Handbook of Industrial Crystallization. 2nd ed.. Elsevier Sci. Technol., 53-54, 93-94. ISBN 0750570126. 